\title{
Natural history of atrial septal defect
}

\author{
Maurice Campbell \\ From the Cardiac Department, Guy's Hospital, London S.E.I, and the Institute of Cardiology, \\ London W.I
}

The natural history of atrial septal defect becomes increasingly difficult to determine with the number of patients having operations. The expectation of life has been calculated for those surviving their first year by two quite independent methods: (I) from I2I reported necropsies and (2) by calculating the mortality rates each decade from 25 deaths among 167 personal or reported patients followed for 663 patient-years. They were patients rather than the ideal of unselected children, but many were symptomless when first seen and sent only because of their physical signs.

The two methods gave close agreement about the percentages still living at the end of each decade, generally within $\pm I$ or 2 per cent and only as much as \pm 4.5 per cent in the second decade. With the relatively small numbers involved, such close agreement is probably fortunate.

The mortality rates are low for the first two decades, 0.6 and 0.7 per cent per annum. In successive decades they rise from 2.7, to 4.5 , to 5.4 , and to 7.5 per cent per annum. One-quarter have died just before their 27th year, half by their 36 th year, three-quarters by 50 , and 90 per cent by 60 years. The arithmetical mean age of death is $37.5 \pm 4.5$ years. The median is also 37 years. The mode is widely spread through the 3rd to 6th decades.

All these figures are better than those for aortic stenosis, coarctation of the aorta, and pulmonary stenosis. In and after the fourth decade they approximate more closely to the figures for aortic stenosis and coarctation but are still better than those for pulmonary stenosis. They are improved on only by those with a persistent ductus.

Atrial septal defect is fairly common: about ro per cent of all cardiac malformations at birth, about 12 per cent of those in children, and over I 5 per cent at clinics for children and adults (Campbell, r968c). The large heart and pulmonary arteries were described by Assmann (1929) and the pulmonary arterial pulsation, the hilar dance, by Pezzi (1925, 1932), though Bedford, Papp, and Parkinson (I94I) and Taussig (1947) emphasized that this was a sign of atrial septal defect quite independently of pulmonary regurgitation.

Two classical papers, the first to collect a long series of necropsies (Roesler, 1934) and the first to report a series of patients studied personally (Bedford et al., 194I), are mentioned here though they will be used more fully later. Brown (1939) wrote 'the lesion is well-tolerated and some patients attain a remarkable age', and 'many subjects are capable of normal activity but others are delicate and lead restricted lives'.

Certainly most children do well for two decades, but this is the only sense in which the Received 2I March 1970. prognosis can be called good. Several papers which give no details that enable me to calculate changes by patient-years make useful comments about prognosis. Wagner and Graham (1957) reported the clinical profiles of 133 children, more than half of whom came to hospital only because of the murmur found at routine examination. They thought the dyspnoea was generally progressive and had four early deaths, excluding those in the first year.

Barber, Magidson, and Wood (1950) found no congestive heart failure in their $\mathbf{4 2}$ patients under 40 years, but it developed in 7 of the 20 over this age. Zaver and Nadas (1965) described 298 patients, 204 under 20 years of age, for the American series on the natural history and profiles of several malformations. They found the average age of onset of congestive heart failure in $4 \mathrm{I}$ patients was much younger, only 25 years. As 18 of them were over 30 , there must have been several children or even infants, but they give no more details. Of their 34 patients who were 'under observation for several years', nearly half had in- 
creasing symptoms, nearly half increasing right ventricular hypertrophy, and nearly half increasing pulmonary $x$-ray changes.

Selzer and Lewis (1949) found most of their cyanotic subjects in the twenties or thirties. Craig and Selzer (1968), studying only patients of 18 or over, found pulmonary hypertension became troublesome mainly in patients between 20 and 48 years (mean of 14 patients, 32 years); but that congestive heart failure generally developed after 40 (mean of 12 patients, 54 years).

Cohn, Morrow, and Braunwald (1967) were concerned mainly with the results of operations on 175 patients, mostly between 14 and 39 years. All but 25 had significant symptoms, most commonly exertional dyspnoea, and there were 29 with or verging on congestive heart failure. Woolf (1963) thought that moderate or severe dyspnoea occurred almost exclusively in those with high pulmonary arterial pressure, but that this could be purely hyperkinetic or due to high pulmonary arterial resistance.

\section{Series where mortality rates can be cal- culated for decades}

Few series of patients followed systematically have been reported. Campbell, Neill, and Suzman (1957) described the progress of 100 patients by decades, but did not then realize the precision that might have been added by calculating mortality rates from patient-years, the total of the number of years each patient was under observation. Most of our patients were over 3 years of age. Known cases with ostium primum defects were omitted, but a few may have been included, as were some who had also partial anomalous pulmonary venous drainage. The patients are far from the ideal of an unselected community, but there do not seem to be any series nearer this ideal. The children and indeed most patients in the first two decades were nearer it than might be thought. Nearly all were getting on well, and many were sent only because a murmur or a large heart had been found at routine school examinations. The fact that more unfit children were not seen at my clinics proves, I think, that there are relatively few such children with atrial septal defect. No series of unselected schoolchildren with atrial septal defect seems to have been reported.

The patient-years in each decade have now been obtained from my notes of these roo patients and the mortality rates calculated (Table I). As usual, I am omitting the heavy mortality of the first year of life and considering only those who survived this period.
TABLE I Calculation of mortality rates each decade for atrial septal defect from series of Campbell et al. (1957)

\begin{tabular}{lllll}
\hline Decade & Patients & $\begin{array}{l}\text { Patient- } \\
\text { years }\end{array}$ & Deaths & $\begin{array}{l}\text { Mortality } \\
\text { rates \% } \\
\text { per annum }\end{array}$ \\
\hline Ist & 33 & 148 & I & $0 \cdot 7$ \\
2nd & I9+(10) & I61 & I & $0 \cdot 6$ \\
3rd & $15+(6)$ & 71 & 2 & $2 \cdot 8$ \\
4th & $20+(4)$ & 64 & 4 & $6 \cdot 3$ \\
5th & $10+(2)$ & 47 & 3 & $6 \cdot 3$ \\
6th and & $3+(2)$ & 32 & 3 & $9 \cdot 4$ \\
$\quad$ after & $3+(2)$ & 523 & 14 & $2 \cdot 7$
\end{tabular}

$\star$ The figures in parentheses are the patients who were also under observation in another decade.

First two decades All but 3 of 52 patients in these decades were doing well, and were leading normal lives with few, if any, symptoms in spite of their very large hearts. Among the 3 who were not doing well there were, however, 2 deaths. One in 148 patientyears in the first decade gives a mortality-rate of 0.7 per cent per annum, and $I$ in $16 \mathrm{r}$ patient-years in the second a rate of 0.6 per cent (see Table I). I think these low rates are only slightly, if at all, worse than the natural prognosis. They are better than I have found for most other cardiac malformations and only a little worse than for persistent ductus arteriosus (Campbell, I968a, b, 1969).

I have found no other figures for these decades and most writers give a good prognosis. Dexter (1956) in an excellent paper on haemodynamic aspects of atrial septal defect also found nearly all his patients doing well. His Fig. 3 and 6 show that the arterial $\mathrm{O}_{2}$ and the pulmonary vascular resistance, two main indications of future trouble, are, with hardly an exception, normal in these decades.

Third and fourth decades These are very different. Dexter (1956) found the two parameters just mentioned had become abnormal in one-third but remained normal in twothirds in the third decade. In the fourth the pulmonary vascular resistance was abnormal in two-thirds and the arterial $\mathrm{O}_{2}$ was abnormal in half. Three of Dexter's patients in these decades had been recatheterized after 7, 7, and 2 years, and showed an average fall of arterial $\mathrm{O}_{2}$ from 95 to 85 per cent. The last did not show much change in the pulmonary vascular resistance, but the two former and a fourth patient showed large increases, with decreases in the right ventricular output. Besterman (I96I) found a pulmonary arterial 
systolic pressure over $50 \mathrm{~mm}$. 'rare below the age of 20 and relatively common after 40', and quoted Bedford and Sellors (1960) as finding it in 4 per cent of those under 20,18 per cent between 20 and 40, and 40 per cent over 40 years among 300 consecutive patients.

Two-thirds of our patients in the third decade were still doing well, but the main complications were beginning to appear. Some were cyanotic from reversal of the shunt following raised pulmonary arterial and rightsided pressure; a few developed congestive heart failure, often a year or two after the onset of atrial fibrillation; and, less important, a few developed pulmonary regurgitation. Two of 21 patients died in 71 patient-years, a mortality rate of 2.8 per cent per annum.

In the fourth and later decades these complications were much more common. More than half the patients seen were severely disabled. In the fourth, 4 of the 24 patients died in 64 patient-years, a mortality rate of 6.3 per cent per annum.

I am sure much higher mortality-rates are correct but not sure that they should be quite as high as these. I did not feel this hesitation about my patients with coarctation because many who died had come under my observation in apparently good health only a few years before, especially those who died with aortic rupture or intracranial haemorrhage. Patients with atrial septal defect generally go downhill more gradually, and few came under my observation in these decades while they were still feeling fit. There was, however, one woman who seemed well at first but died within two years with sudden left ventricular failure.

I have found no other series where the patient-years and mortality-rates can be calculated for any of the first four decades, but Craig and Selzer (1968) give some useful information.

Craig and Selzer's estimates of life expectation In 128 of their patients, all 18 years or over, 14 per cent developed pulmonary hypertension in the third or fourth decades. Craig and Selzer compared the age distribution of $65 \mathrm{I}$ personal and reported patients with atrial septal defect, all in the third to seventh decades, with the distribution to be expected among 65I normal subjects (Table 2).

From these figures they concluded that the expectation of life for those with atrial septal defect is greatly reduced in the third and fourth decades and enormously so in the fifth and later decades. Some calculations I have made from these figures suggest that the mortality
TABLE 2 Age, distribution of 651 patients with atrial septal defect compared with normal subjects

\begin{tabular}{|c|c|c|c|c|c|}
\hline Decades & $3 r d$ & $4 t h$ & $5 t h$ & 6 th & 7 th \\
\hline \multirow{2}{*}{$\begin{array}{l}\text { Predicted normals } \\
\text { Patients with atrial } \\
\text { septal defect }\end{array}$} & I4I & 140 & 135 & 129 & 106 \\
\hline & 210 & I74 & 156 & 88 & 23 \\
\hline
\end{tabular}

rates were probably about 2.6 per cent per annum in the third and fourth decades, about 4.4 per cent in the fifth decade, and about 7.3 per cent per annum in the sixth decade.

Fifth and sixth decades Of our patients in the fifth decade, 2 died, and I with congestive failure who died towards the end of the fourth decade after an operation is counted here as she would probably have lived a few more years; 3 deaths in 47 patient-years gives a mortality-rate of 6.3 per cent per annum.

In the sixth and later decades, 3 more died in 32 patient-years, a mortality-rate of 9.4 per cent per annum. One had been quite well till the onset of atrial fibrillation at 56 and lived to be 63 years old.

For these decades, there is a more valuable paper with full details of the patient-years by Markman, Howitt, and Wade (I965) on atrial septal defect in middle-aged and elderly patients. Unfortunately they did not extend their observations to the third and fourth decades. Their results are shown in Table 3 with

TABLE 3 Mortality rates calculated from Markman et al. (1965)

\begin{tabular}{|c|c|c|c|c|c|}
\hline $\begin{array}{l}\text { Age } \\
\text { (yr.) }\end{array}$ & $\begin{array}{l}\text { No } \\
\text { pat } \\
\text { pat }\end{array}$ & ts and & $\begin{array}{l}\% \\
\text { seriously } \\
\text { disabled }\end{array}$ & $\begin{array}{l}\text { No. of } \\
\text { deaths }\end{array}$ & $\begin{array}{l}\text { Mortality } \\
\text { rates } \% \\
\text { per annum }\end{array}$ \\
\hline $\begin{array}{l}40-45 \\
46-50 \\
5 I-55 \\
56-60 \\
6 I-65 \\
66-70\end{array}$ & $\begin{array}{r}20 \\
15 \\
12 \\
12 \\
5 \\
3\end{array}$ & $\begin{array}{r}125 \\
81 \\
46 \\
53 \\
24 \\
17\end{array}$ & $\left.\begin{array}{l}\left.\begin{array}{l}12 \\
21\end{array}\right\} 17 \\
31 \\
50\end{array}\right\} 40$ & $\begin{array}{l}\left\{\begin{array}{l}I \\
2\end{array}\right. \\
\left\{\begin{array}{l}3 \\
4\end{array}\right. \\
I\end{array}$ & $\left.\begin{array}{l}0 \cdot 8 \\
2 \cdot 5 \\
6 \cdot 5 \\
7 \cdot 7 \\
2 \cdot 4\end{array}\right\} 5 \cdot 7$ \\
\hline Total & 67 & 346 & 33 & I I & $3 \cdot 2$ \\
\hline
\end{tabular}

my calculations of the mortality rates added. They give a more favourable picture than my series for both decades, enormously more favourable for the fifth decade. The percentage who were 'seriously disabled' increases greatly in each half-decade, from 12 to 87 per cent, but even here they fared much better than my patients in the fifth decade. Coulshed andLittler (1957) reported 5 elderly patients who had 
noticed few symptoms till the sixth decade, including an interesting man in his sixties who had worked as a fitter for 40 years with no time off though his heart had been enlarged as a child.

The true mortality rates must lie somewhere between these findings and mine shown in Table I. I think Markman et al.'s centre may have unconsciously excluded some of the more ill patients because it was not so closely associated with surgical treatment, but they could say this association made my results much too unfavourable.

Dexter (1956) found that arterial $\mathrm{O}_{2}$ saturation and pulmonary vascular resistance were both abnormal in two-thirds of their patients in the fifth as well as the sixth decade. This and the apparently high mortality rate shown by the figures of Craig and Selzer (1968) make me think that my figures for the fifth decade are nearer the truth than those of Markman et al. (1965).

\section{Calculation of expectation of life}

The figures available for mortality rates for this calculation are shown in Table 4. For the first three decades the only drawback is that they depend almost entirely on my own series. I have, however, mentioned some supporting evidence. For the sixth decade and after, the three estimates vary widely but they are all high and it seems reasonable to take the average.

The fourth and fifth decades are more difficult. An average of two such different figures in the fourth decade may be very approximate. In the fifth decade the figure of Markman et al. (1965) is so much lower that using it for a mean figure brings this decade quite out of line with the preceding and following decades. I have, therefore, reluctantly decided to omit these 3 deaths in 206 patient-years and to use the mean of the other two estimates only.

With these drawbacks, it may seem unreasonable to attempt any calculations of the expectation of life. I should hesitate to publish the results if there were any prospect of someone being able to produce more reliable mortality rates. This, however, seems extremely unlikely with the number of patients who now have operations.

I have, therefore, used the mortality rates shown in the last column of Table 4 to calculate the expectation of life, emphasizing that this is an approximation rather than a true life table. The number of deaths was calculated for each year, but only those for the last year of each decade are shown in the second line of Table 5 .

The expected number of deaths for each I000 normal subjects living at I year are
TABLE 4 Combined mortality rates for patients with atrial septal defects

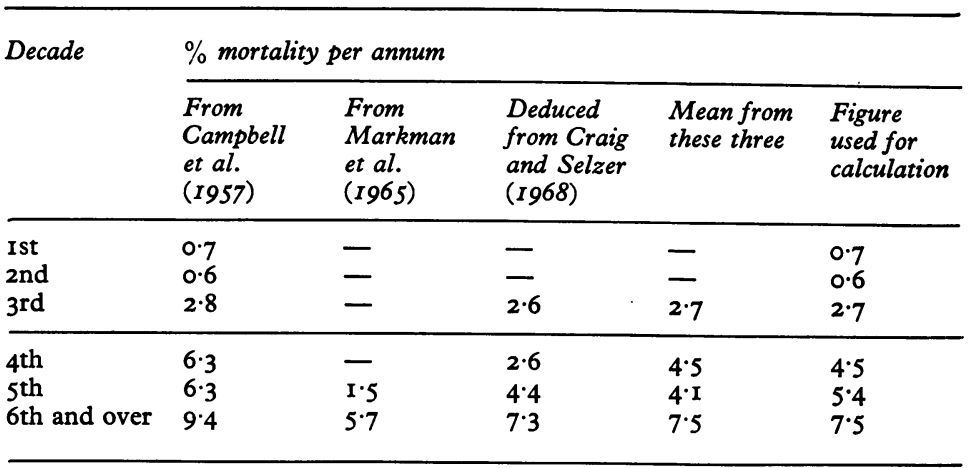

TABLE 5 Calculated expected deaths and survivors from 1000 subjects with atrial septal defect alive at I year

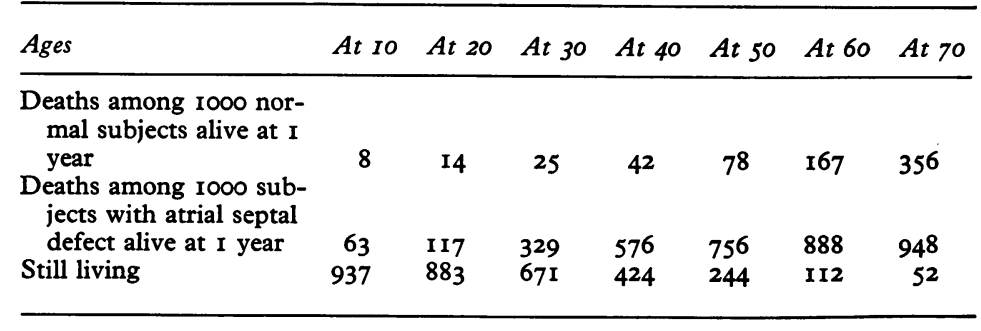

shown in the top line of Table 5. They are taken from Life Table No. I I of the Registrar General (1957) adjusted for an imaginary population where there are two women for each man, to allow for the differential sex incidence of atrial septal defect.

The second line shows the calculated deaths per rooo subjects with atrial septal defect, who were still living at the age of I year. The mortality in the first year is very high, about 30 per cent (Campbell, 1968c) but not as high as with several other cardiac malformations. During the rest of the first two decades, the mortality is about 8 times as high as the expected normal, in the third and fourth about I3 times as high, and in the fifth decade Io times as high, and after this as the deaths increase in the normal population only about 4 times as high. The last line of Table 5 shows the number living at the end of each decade.

The Fig. shows the number dying in each decade with atrial septal defect compared with normal subjects up to 67 years of age when the normal curve rises outside the figure. Of patients with atrial septal defect, one-quarter have died before they are 27 years, half by 37 years, three-quarters by 50 years, and 90 per cent just after 60 years. These 
figures are considerably better than those for coarctation of the aorta for the first three decades but not much better after 40 years of age.

We shall next consider a completely independent method for estimating the expectation of life.

\section{Age at death in reported necropsies}

For coarctation of the aorta, my number of deaths calculated by patient-years could be compared with the ages at death in 304 reported necropsies. Either method should be accurate if the subjects studied are representative of the general population with the malformation in question. These two completely independent methods provided results of the same order, in closer agreement than seemed probable when my calculations were made on only 716 patient-years.

For atrial septal defect my patient-years are only 663 years, and I can find no large collection of reported necropsies since the 62 cases of Roesler with a mean age of death of 36 years. These are shown by decades in the first line of Table 6 . The second line shows the only subsequent series I have been able to find where the ages of 59 subjects are given - the 9 cases of McGinn and White (1933) not included in Roesler's series; Io of Bedford $e t$ al. (194I); 25 of Welch and Kinney (1948); and 15 cases of Campbell et al. (1957).

The total I2I deaths are shown in the third line and, again, reduced to percentages in the fourth line. Seventy per cent of the deaths were fairly equally distributed between the third, fourth, fifth, and sixth decades. The last three lines show the cumulative percentage of deaths at the end of each decade (a) from the reported necropsies shown above, (b) from calculations from mortality rates of observed patients shown in Table 5, and (c) the mean of these two estimates with the range of variation.

There is such good agreement that it seems almost certain that the true figure is somewhere between these. The difference is never outside \pm 4.5 per cent, and in the fourth decade and after the true figure can be expressed as percentages $\pm \mathrm{I}$. With the relatively small numbers available for both these calculations, the agreement is again almost certainly closer than could reasonably have been expected.

The mean age of death was given in three other series where the patients could not be distributed between decades. Abbott (1936) had 68 patients with a mean age of 27 years, Burrett and White (1945) 3I patients with a mean age of 37 years, and Cosby and Griffith (1949) I9 patients with a mean age of 49 years. I could not include papers dealing predomin-
FIG. Percentage mortality of subjects with atrial septal defect in each decade. The figures for reported necropsies are shown by open squares and those for my calculated deaths by closed triangles. The curve is drawn as nearly as possible through the mean of these two sets of figures. It shows that nearly three-quarters of the deaths $(73.6 \%)$ take place in the third to sixth decades, and are fairly equally distributed between these four decades.

The lower curve, which is near the baseline (no deaths) up to 35 years, represents the percentage of deaths that occur in normal subjects up to the age of 67 years when the curve leaves the area of the figure. The two curves cross at 58 years when nearly 90 per cent of those with atrial septal defect have died ( 89.8 at 60), but only I6 per cent of normal subjects.

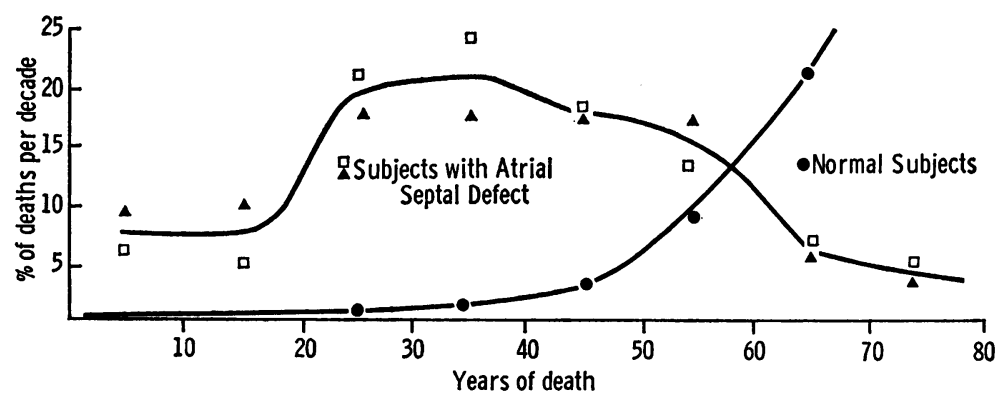

antly with children or the 53 years of the II patients of Markman et al. (I965), because they started only with patients who were still alive at 40 years. The mean age of the 118 patients in the three series above was 33 years.

The arithmetical mean age at death for the I2I reported necropsies was 38 years, and for the 132 patients used for my calculation $4 \mathrm{I}$ years - perhaps too high because of the use of

TABLE 6 Ages of patients with atrial septal defect at I 21 reported necropsies, by decades

\begin{tabular}{|c|c|c|c|c|c|c|c|}
\hline Decades & Ist & 2nd & $3 r d$ & 4 th & 5 th & 6 th & $\begin{array}{l}\text { 7th or } \\
\text { later }\end{array}$ \\
\hline \multirow{2}{*}{$\begin{array}{l}62 \text { cases of Roesler (1934) } \\
59 \text { other reported cases } \\
\text { (see text) }\end{array}$} & 5 & 8 & 15 & 9 & 10 & 10 & 5 \\
\hline & 7 & 5 & 7 & 12 & I I & II & 6 \\
\hline \multirow{5}{*}{$\begin{array}{l}\text { Total I2I cases } \\
\text { Expressed as \% } \\
\text { (a) \% dead at end of } \\
\text { each decade } \\
\text { (b) Calculated deaths } \\
(\%) \text { from Table } 5 \\
\text { (c) Probable correct } \\
\text { range of deaths } \\
(\%)\end{array}$} & 12 & 13 & 22 & 21 & 21 & 21 & II \\
\hline & $9 \cdot 9$ & 10.7 & $18 \cdot 1$ & $17 \cdot 4$ & $17 \cdot 4$ & $17 \cdot 4$ & $9 \cdot 1$ \\
\hline & $9 \cdot 9$ & $20 \cdot 6$ & $38 \cdot 7$ & $56 \cdot I$ & 73.5 & 90.9 & $96 \cdot 7^{\star}$ \\
\hline & $6 \cdot 3$ & II $\cdot 7$ & $32 \cdot 9$ & $57 \cdot 6$ & $75 \cdot 6$ & $88 \cdot 8$ & $94^{-8 *}$ \\
\hline & $8 \pm 2$ & $16 \pm$ & $536 \pm 3$ & $57 \pm I$ & $74 \cdot 5$ & I $90 \pm I$ & $96 \pm I^{x}$ \\
\hline
\end{tabular}

$\star$ These figures are for the end of the seventh decade. 
some patients of Markman et al. From the 37I patients in these three groups it seems reasonably certain that the true mean is $37.5 \pm 4.5$ years. The median is 37 for the calculated deaths and just under 37 years for the reported necropsies. The mode for both groups is wide, between 20 and 55 years. All these are a little older than the corresponding figures for coarctation of the aorta, between about 4 and 6 years.

I was interested to see that the mean age at death of 55 acromegalics was 57 years, older than any of my groups with cardiac malformations, but they had not, of course, had the condition all their lives (Wright et al., 1970).

\section{Ostium primum defects}

I could not have written this section without the paper of Somerville (I965). Omitting her two infants who died during their first year, there were 120 patients. Of these, Io died and I5 were seriously disabled. She emphasized the difference between those under and those over 30 years of age. Under 30, there were 3 deaths and 8 seriously disabled out of 94 (12\%), but over 30 there were 7 deaths and 7 seriously disabled out of 26 ( $54 \%$ ).

The distribution of these patients is shown in Table 7. The two bottom lines show the proportion of dead or seriously disabled, and the cumulative number of those in these two groups at the end of each decade. The mean age of those who had died was 36 years and of those seriously disabled 31 years. It seems unlikely that these last would have lived very long, and the mortality is a little, but not much, worse than for those with ostium secundum defects - a wonderful example of the capacity of the heart to cope with complicated malformations. Blount, Balchum, and Gensini (1956) found they had larger hearts and symptoms earlier than those with secundum defects. Bedford (1960) found ostium
TABLE 7 Deaths and serious disabilities in 120 patients with ostium primum defects (Somerville, 1965)

\begin{tabular}{|c|c|c|c|c|c|c|c|c|}
\hline Decades & Ist & 2nd & $3 r d$ & $4 t h$ & 5th & $6 t h$ & $7 t h$ & All \\
\hline $\begin{array}{l}\text { No. of patients } \\
\text { Deaths (a) } \\
\text { Serious disability (b) } \\
(\text { a) }+(b) \\
\text { Proportion of }(a)+(b) \text { to } \\
\quad \text { total } \\
\text { Cumulative (a) }+(b) \\
\text { percentages }\end{array}$ & $\begin{array}{l}24 \\
2 \\
3 \\
5 \\
1 / 5 \\
20\end{array}$ & $\begin{array}{c}47 \\
0 \\
2 \\
2 \\
I / 25\end{array}$ & $\begin{array}{l}23 \\
1 \\
3 \\
4 \\
\\
1 / 6\end{array}$ & $\begin{array}{r}13 \\
3 \\
3 \\
6\end{array}$ & $\begin{array}{l}5 \\
1 \\
2 \\
3 \\
1 / 2\end{array}$ & $\begin{array}{l}7 \\
2 \\
2 \\
4 \\
1 / 2\end{array}$ & $\begin{array}{l}\text { all } \\
\text { I00 }\end{array}$ & $\begin{array}{r}120 \\
10 \\
15 \\
25 \\
-\end{array}$ \\
\hline
\end{tabular}

primum defects were only 10.3 per cent of all his 300 patients having operations for atrial septal defects instead of over 20 per cent in some clinics dealing only with children.

There was no differential sex incidence in Somerville's series; but of eight patients who lived after 40, all three men died in their forties, four women in their fifties, and the last woman in her sixties.

Pulmonary hypertension seemed less important than in ostium secundum defects. It was present in only 2 of the 25 dead or seriously disabled subjects, while Wood (1958) found fully developed Eisenmenger's syndrome in nearly 8 per cent of all patients with atrial septal defect.

Atrial fibrillation often starts the deterioration in patients with ostium secundum defects, but arrhythmias seemed more important in starting deterioration in ostium primum defects - in 15 of the 25 patients, 6 having atrial fibrillation and 6 complete heart block.

Bacterial endocarditis occurred in 3 of her I20 patients. Supposing all attacks during their lives were recorded, which seems unlikely, this would be in 2712 patient-years, for the mean age was 22.6 years. This would give an attack rate of at least 0.1 per cent per

TABLE 8 Calculated approximate percentage of deaths (by two methods) for various cardiac malformations at end of each decade

\begin{tabular}{|c|c|c|c|c|c|c|c|}
\hline & At ro & At 20 & At 30 & At 40 & At 50 & At 60 & At 70 \\
\hline $\begin{array}{l}\text { Normal subjects } \\
\text { Persistent ductus }\end{array}$ & $\begin{array}{l}0.8 \\
4.4\end{array}$ & $\begin{array}{l}I \cdot 4 \\
8 \cdot 8\end{array}$ & $\begin{array}{l}2 \cdot 6 \\
20^{\star}\end{array}$ & $\begin{array}{r}4.4 \\
33 \cdot 5\end{array}$ & $\begin{array}{l}8 \cdot 3 \\
50\end{array}$ & $\begin{array}{l}18 \\
61\end{array}$ & $\begin{array}{l}39 \\
67^{\star}\end{array}$ \\
\hline Atrial septal defect & $\begin{array}{l}44 \\
6 \cdot 3\end{array}$ & 12 & 33 & $\begin{array}{l}530 \\
57 \cdot 5\end{array}$ & 75.5 & 89 & 95 \\
\hline Aortic stenosis & 10 & 20.5 & $41 \cdot 5$ & 59 & 78 & $9 \mathrm{I}$ & 96 \\
\hline Coarctation & 13.5 & 26.5 & 44.5 & 60.5 & 80 & 90 & 95 \\
\hline Pulmonary stenosis & 16.5 & 32 & 52 & 74 & 87.5 & 94 & 97 \\
\hline $\begin{array}{l}\text { Coarctation of aorta } \\
\text { Atrial septal defect }\end{array}$ & $\begin{array}{l}9 \pm 4 \cdot 5 \\
8 \pm 2\end{array}$ & $\begin{array}{l}26 \pm 0.5 \\
16 \pm 4.5\end{array}$ & $\begin{array}{l}47 \pm 2 \\
36 \pm 3\end{array}$ & $\begin{array}{l}65 \pm 4 \\
57 \pm 1\end{array}$ & $\begin{array}{l}83 \pm 3 \cdot 5 \\
74 \pm 1\end{array}$ & $\begin{array}{l}91 \cdot 5 \pm I \cdot 5 \\
90 \pm I\end{array}$ & $\begin{array}{l}96 \pm I \\
96 \pm I\end{array}$ \\
\hline
\end{tabular}

* By 30 years, 15 per cent have a closed ductus with a normal expectation of life, and by 60 years, 20 per cent. 
annum which would be much more than in ostium secundum defects, but much less than in most other cardiac malformations, $0.9 \pm 0.4$ per cent per annum (Campbell, 1970).

\section{Comparison with other cardiac malfor- mations}

I have now been able to calculate the mortality rates and expectation of life for 5 of the commoner cardiac malformations (Table 8). Persistent ductus has the best outlook in every decade, even without allowing for the 20 per cent where the duct closes spontaneously.

Atrial septal defect, congenital aortic stenosis, and coarctation come next, and there is little difference in these three in and after the fourth decade. Atrial septal defect has a much better outlook for the first three decades, but after this its advantage diminishes. Aortic stenosis has a better outlook than coarctation in the first and second decades but only a little better in the third and later.

Surprisingly to me, pulmonary stenosis had the worst outlook of these five malformations. I think, however, that the evidence, including haemodynamic evidence of the rate of rise of right ventricular pressure with pulmonary stenosis, favours this view.

\section{References}

Abbott, Maud (1936). Atlas of Congenital Cardiac Disease. American Heart Association, New York.

Assmann, H. (1929). Die klinische Röntgendiagnostik der inneren Erkrankungen, 4th ed. Vogel, Leipzig.

Barber, J. M., Magidson, O., and Wood P. (1950). Atrial septal defect, with special reference to the electrocardiogram, the pulmonary artery pressure and the second heart sound. British Heart fournal, 12, 277.

Bedford, D. E. (1960). The anatomical types of atrial septal defect: their incidence and clinical diagnosis. American fournal of Cardiology, 6, 568.

- Papp, C., and Parkinson, J. (I94I). Atrial septal defect. British Heart fournal, 3, 37.

-, and Sellors, T. H. (1960). Atrial septal defect. In Modern Trends in Cardiology, p. 138. Ed. by A. Morgan Jones. Butterworth3, London.

Besterman, E. (I96I). Atrial septal defect with pulmonary hypertension. British Heart fournal, 23, 587.

Blount, S. G., Balchum, O. J., and Gensini, G. (1956). The persistent ostium primum atrial septal defect. Circulation, 13, 499.

Brown, J. W. (1939). Congenital Heart Disease. John Bale Medical Publications, London.

Burrett, J. B., and White, P. D. (1945). Large interauricular septal defect with particular reference to diagnosis and longevity. American fournal of the Medical Sciences, 209, 355.

Campbell, M. (1968a). Natural history of persistent ductus arteriosus. British Heart fournal, 30, 4 .
- (1968b). The natural history of congenital aortic stenosis. British Heart fournal, 30, 514 .

- (1968c). The incidence and later distribution of malformations of the heart. In Paediatric Cardiology, p. 71. Ed. by Hamish Watson. Lloyd-Luke (Medical Books), London.

(1969). Natural history of congenital pulmonary stenosis. In Aloisio Condorelli. LXX. Aetatis Annum feliciter conficienti ex omnibus nationibus docti viri scripta ad medicinam pertinentia honoris causa collecta, p. 69. Rome.

- (1970). Natural history of coarctation of the aorta. British Heart fournal, 32, 633.

-, Neill, C., and Suzman, S. (1957). The prognosis of atrial septal defect. British Medical fournal, r, 1375.

Cohn, L. H., Morrow, A. G., and Braunwald, E. (1967). Operative treatment of atrial septal defect: clinical and haemodynamic assessments in 175 patients. British Heart fournal, 29, 725.

Cosby, R. S., and Griffith, G. C. (I949). Interatrial septal defect. American Heart fournal, 38, 80.

Coulshed, N., and Littler, T. R. (1957). Atrial septal defect in the aged. British Medical fournal, $\mathbf{1}, 76$.

Craig, R. J., and Selzer, A. (I968). Natural history and prognosis of atrial septal defect. Circulation, 37, 805 .

Dexter, L. (1956). Atrial septal defect. British Heart fournal, 18, 209.

McGinn, S., and White, P. D. (1933). Interauricular septal defect associated with mitral stenosis. American Heart fournal, 9, 1.

Markman, P., Howitt, G., and Wade, E. G. (1965). Atrial septal defect in the middle-aged and elderly. Quarterly fournal of Medicine, 34, 409.

Pezzi, C. (1925). Atti della Società Lombarda di Scienze Mediche e Biologiche, 14, 52.

- (1932). The radioscopic sign of the 'hilum dance'; its clinical significance. In Contributions to the Medical Sciences in Honor of Dr. Emanuel Libman, Vol. 3, p. 931. International Press, New York.

Registrar General (1957). Decennial Supplement, England and Wales, 1951. Life Tables, pp. 31-34

Roesler, H. (1934). Interatrial septal defect. Archives of Internal Medicine, 54, 339.

Selzer, A., and Lewis, A. E. (I949). The occurrence of chronic cyanosis in cases of atrial septal defect. American fournal of the Medical Sciences, 218, 516.

Somerville, Jane (1965). Ostium primum defect: factors causing deterioration in the natural history. British Heart fournal, 27, 413.

Taussig, Helen B. (1947). Congenital Malformations of the Heart. The Commonwealth Fund, New York.

Wagner, Joan, and Graham, G. R. (1957). Atrial septal defect in children. British Heart fournal, 19, 318

Welch, K. J., and Kinney, T. D. (1948). The effect of patent ductus arteriosus and of interauricular and interventricular shunts on the development of pulmonary vascular lesions. American fournal of Pathology, 24, 729.

Wood, P. (1958). The Eisenmenger syndrome or pulmonary hypertension with reversed central shunt. British Medical fournal, 2, 701 and 755.

Woolf, C. R. (1963). Pulmonary function in adults with intracardial septal defect. Circulation, 27, 26r.

Wright, A. D., Hill, D. M., Lowy, Clara, and Fraser, T. R. (1970). Mortality in acromegaly. Quarterly fournal of Medicine, 39, $\mathrm{I}$.

Zaver, A. G., and Nadas, A. S. (1965). Atrial septal defect - secundum type. Circulation, 32, Suppl. 3, p. 24 . 